\title{
Preparation of Highly Oriented Bismuth Titanate Thin Films by Sol-Gel Process
}

\author{
Eiji KATO, Yuichi WATANABE, Takeyo TSUKAMOTO* and Toshio TSUCHIYA \\ Faculty of Industrial Science and Technology, Science University of Tokyo, 2641, Yamazaki, Noda-shi, Chiba 278 \\ *Faculty of Science, Science University of Tokyo, 1-3, Kagurazaka, Shinjuku-ku, Tokyo 162
}

\author{
ゾル・ゲル法による高配向したチタン酸ビスマス薄膜の作製 \\ 加藤英治・渡辺裕一・塚本桓世* $*$ 土谷敏雄 \\ 東京理科大学基礎工学部材料工学科, 278 千葉県野田市山崎 2641 \\ *東京理科大学理学部応用物理学科, 162 東京都新宿区神楽坂 1-3
}

\begin{abstract}
In the present study, an attempt is made to prepare a highly $c$-axis oriented thin film with the composition of $\mathrm{Bi}_{4} \mathrm{Ti}_{3} \mathrm{O}_{12}$ (BIT). Bismuth nitrate and titanium tetrabutoxide were used as raw materials. Acetylacetone and ethylene glycol were used as the solvents. The thin film was a single phase of BIT completely oriented along the $c$-axis on Pt substrate with good ferroelectric properties at room temperature : coercive field of $25 \mathrm{kV} /$ $\mathrm{cm}$, remanent polarization of $2.5 \mu \mathrm{C} / \mathrm{cm}^{2}$, dielectric constant of 130 . The key technique to highly $c$-axis oriented thin films was heat treatment of sol prepared by optimum combination of raw materials and solvents.
\end{abstract}

[Received March 6, 1996; Accepted August 6, 1996]

Key-words : $\mathrm{Bi}_{4} \mathrm{Ti}_{3} \mathrm{O}_{12}(\mathrm{BIT})$ thin film, Highly c-axis oriented thin film, Ferroelectric, Sol-gel process

\section{Introduction}

Bismuth titanate $\mathrm{Bi}_{4} \mathrm{Ti}_{3} \mathrm{O}_{12}$ (BIT) with chemical formula such as $\left(\mathrm{Bi}_{2} \mathrm{O}_{2}\right)^{2+}\left(\mathrm{A}_{m-1} \mathrm{~B}_{m} \mathrm{O}_{3 m+1}\right)^{2-}$ is a ferroelectric oxide with a layered structure with exhibits the polarization-electric field $(P-E)$ switching behavior necessary for memory application in bulk ceramic form. ${ }^{1)}$ BIT has a Curie temperature of $675^{\circ} \mathrm{C}$, allowing poled polycrystals to maintain a remanent polarization state up to at least $400^{\circ} \mathrm{C}$, thereby avoiding the thermal imprint (thermal depolarization) problem. The rather unique orthorhombic structure of BIT offers another advantage. The spontaneous polarization vector lies in the $b-c$ plane at an angle of $4.5^{\circ}$ to the $b$-axis. As a result, two independently reversible components are observed, one with a remanent polarization of $50 \mu \mathrm{C} / \mathrm{cm}^{2}$ along the $b$-axis, and one with $4 \mu \mathrm{C} / \mathrm{cm}^{2}$ along the $c$-axis. ${ }^{2)}$ The coercive fields are $50 \mathrm{kV} / \mathrm{cm}$ and $3.5 \mathrm{kV} / \mathrm{cm}$, and the dielectric constants are 160 and 130 , respectively, along $b$ and $c$-axis. ${ }^{3)}$ The coercive field along $c$-axis of BIT is lower than that of PZT. So, the $c$-axis oriented BIT thin films are very suitable as non-destructive readout (NDRO) materials having metal/ferroelectric/semiconductor (MFS) structure.

A variety of processing techniques have been attempted for the fabrication of BIT thin films, including $\mathrm{rf}^{4)}$ and ESR plasma sputtering ${ }^{5)}$ and sol-gel method.6) Same groups beside have prepared BIT films using a sol-gel technique; however no $c$-axis orientation has been observed. ${ }^{7)}$ Fuierer et al. reported that the solution aged for 60 days yielded highly [001] oriented BIT from sol-gel technique. But the degree of orientation of the films prepared from an aged solution was calculated from the relative peak heights to be $51 \% .^{8)}$

Buhay et al. ${ }^{9)}$ produced BIT films by pulsed laser ablation deposition (PLD) at processing temperatures as low as $500^{\circ} \mathrm{C}$ on $\mathrm{Si}$ and Pt-coated Si substrates. These were polycrystalline films with $\operatorname{Pr}$ of $19 \mu \mathrm{C} / \mathrm{cm}^{2}$ and large $E_{\mathrm{c}}$ of 200 $\mathrm{kV} / \mathrm{cm}$. Maffei and Krupanidhi has succeeded in growing partially $c$-axis oriented BIT on Pt-coated Si substrates at $600^{\circ} \mathrm{C}$, resulting in fully saturated hysteresis loops with corresponding parameters : $\operatorname{Pr}=7 \mu \mathrm{C} / \mathrm{cm}^{2}$ and $E_{\mathrm{c}}=20 \mathrm{kV} /$ $\mathrm{cm} .{ }^{10)}$

Tsukamoto et al. ${ }^{11)}$ produced BIT thin films by spin-coat- ing pyrolysis of $\mathrm{Bi}$ and $\mathrm{Ti}$ naphthenates and successive heat treatment in $\mathrm{O}_{2}$ gas. The thin film was a single phase of BIT completely oriented along the $c$-axis with good ferroelectric properties at room temperature : coercive field of $15 \mathrm{kV} /$ $\mathrm{cm}$, remanent polarization of $1.9 \mu \mathrm{C} / \mathrm{cm}^{2}$, dielectric constant of 43 , and dielectric loss of 0.02 . Heat treatment in $\mathrm{O}_{2}$ gas at high pressure was effective for the fabrication of $c$ axis oriented BIT thin films with a smooth surface and the improvement of their properties : leakage current density on the order of $10^{-9} \mathrm{~A} / \mathrm{cm}^{2}$. The remanent polarization of the thin film was kept constant up to the polarization reversal at $1 \times 10^{7}$ cycles. ${ }^{12)}$ But these method needs heat treatment in $\mathrm{O}_{2}$ gas at high pressure.

Moreover, Tsukamoto et al. ${ }^{13)}$ produced ferroelectric BIT thin films by the metal-organic chemical vapor deposition (MOCVD) method at atmospheric pressure using $\mathrm{Bi}\left(0-\mathrm{C}_{7} \mathrm{H}_{7}\right)_{3}$ and $\mathrm{Ti}\left(i-\mathrm{OC}_{3} \mathrm{H}_{7}\right)_{2}(\mathrm{DPM})_{2}$ as metal-organic sources. Completely $c$-axis oriented BIT thin films were prepared on $\mathrm{Pt}$ plates heat-treated at $600^{\circ} \mathrm{C}$, which showed good ferroelectric properties : remanent polarization of 1.0 $\mu \mathrm{C} / \mathrm{cm}^{2}$, coercive field of $18 \mathrm{kV} / \mathrm{cm}$ and leakage current on the order of $10^{-9} \mathrm{~A} / \mathrm{cm}^{2}$. But this method contains a very complicating treatment on raw materials and procedure. Especially, the sol-gel process has received much interest due to the potential of high precision control of chemical stoichiometry, homogeneity, low temperature processing and decreasing costs. In the present study, an attempt is made to prepare highly $c$-axis oriented BIT thin films on $\mathrm{SiO}_{2} / \mathrm{Si}$ and platinum substrates by sol-gel process, and the electric properties of the obtained films were measured.

\section{Experimental}

\subsection{Preparation of coating solution}

Coating solutions and thin films were prepared as shown in Fig. 1. Bismuth nitrate pentahydrate, $\mathrm{Bi}\left(\mathrm{NO}_{3}\right)_{3} \cdot 5 \mathrm{H}_{2} \mathrm{O}$ (Wako Pure Chemical Ind., Ltd.) and titanium tetrabutoxide, $\mathrm{Ti}\left(\mathrm{O}\left(\mathrm{CH}_{2}\right)_{3} \mathrm{CH}_{3}\right)_{4}$ (Wako Pure Chemical Ind., Ltd.) were used as raw materials. Acetylacetone (AcAc), $\mathrm{CH}_{3} \mathrm{COCH}_{2} \mathrm{COCH}_{3}$ (Wako Pure Chemical Ind., Ltd.) and ethylene glycol (EG), $\mathrm{CH}_{2}(\mathrm{OH}) \mathrm{CH}_{2} \mathrm{OH}$ (Wako Pure Chemical Ind., Ltd.) were used as solvents. In the first process, bismuth nitrate was dissolved in acetylacetone and 


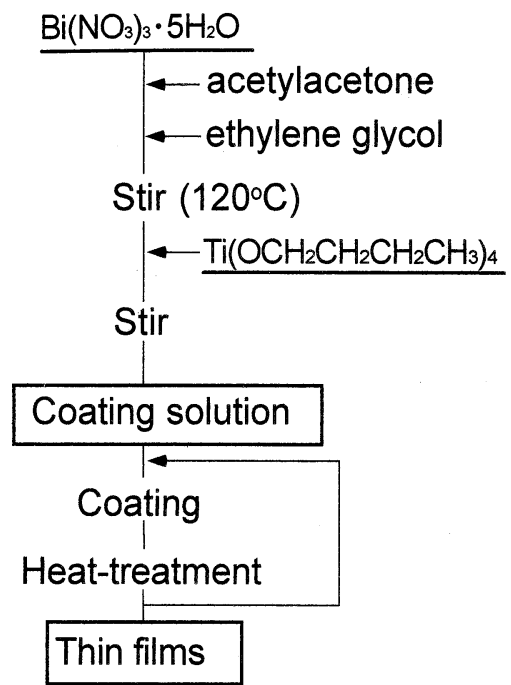

Fig. 1. Preparation procedure of $\mathrm{Bi}_{4} \mathrm{Ti}_{3} \mathrm{O}_{12}$ thin films.

then ethylene glycol was often added, and stirred at $120^{\circ} \mathrm{C}$ for $2 \mathrm{~h}$. After cooling to room temperature, titanium tetrabutoxide was added to the solution.

The thin films were formed on $\mathrm{SiO}_{2} / \mathrm{Si}(100)$ wafer and platinum plate. The coating films were deposited by spincoating at $1500 \mathrm{rpm}$ for $5 \mathrm{~s}$ and $4000 \mathrm{rpm}$ for $15 \mathrm{~s}$. The coating and pre-heat-treating processes were repeated to obtain sufficient thickness for measurement of properties. Then, the films were heated at temperatures from 500 to $800^{\circ} \mathrm{C}$.

\subsection{Analysis}

Infrared spectra (IR) of coating solutions were measured in the wavenumber range from 400 to $2000 \mathrm{~cm}^{-1}$ using a Fourier transform IR spectrophotometer (FT-IR 4200, Rigaku). Crystalline phases of the thin films were identified using an X-ray diffractometer (Rotaflex, CN4148, Rigaku) with $\mathrm{Cu} \mathrm{K} \alpha$ radiation and carbon monochromator. The degree of orientation of BIT polycrystalline thin films was evaluated from the degree of $c$-axis orientation using rocking curves of (008) plane of BIT. The thickness and morphology of the films were measured by scanning electron microscope (SEM, JSM-5800, JEOL), and atomic force microscope (AFM, SPA-300, JEOL), respectively. To measure electric properties, platinum electrodes were deposited onto the top of the films by sputtering. Dielectric constant was calculated from the capacitance measured by an impedance analyzer (HP4194A, Yokokawa). The remanent polarization, $P_{\mathrm{r}}$, and coercive field, $E_{\mathrm{c}}$, were calculated from the $P-E$ hysteresis loops observed with a Sawyer-Tower circuit.

\section{Results and discussion}

\subsection{IR spectra of coating solution}

Figure 2 shows IR spectra of following solutions; (a) mixed solution of AcAc and EG, (b) bismuth nitrate solution which was dissolved in AcAc and then added to ethylene glycol and (c) solution (b) which was the heat treatment at $120^{\circ} \mathrm{C}$. In all spectra, the absorption due to $\mathrm{C}=\mathrm{O}$ stretching vibration appeared at $1620 \mathrm{~cm}^{-1}$ for an acetylacetone existing as enol type and at $1730 \mathrm{~cm}^{-1}$ for an acetylacetone of keto type. But, new peak appeared for the spectra of (b) and (c) of solutions containing bismuth nitrate. The $\mathrm{C}=\mathrm{C}$ vibration of chelate complex appeared at $1500 \mathrm{~cm}^{-1}$. As above mentioned, the homogeneous solution may be attained by the formation of the complex due to substitution by AcAc of metal nitrate.

3.2 X-ray diffraction analysis of thin films

In this study, an attempt is made to prepare a highly $c$ -

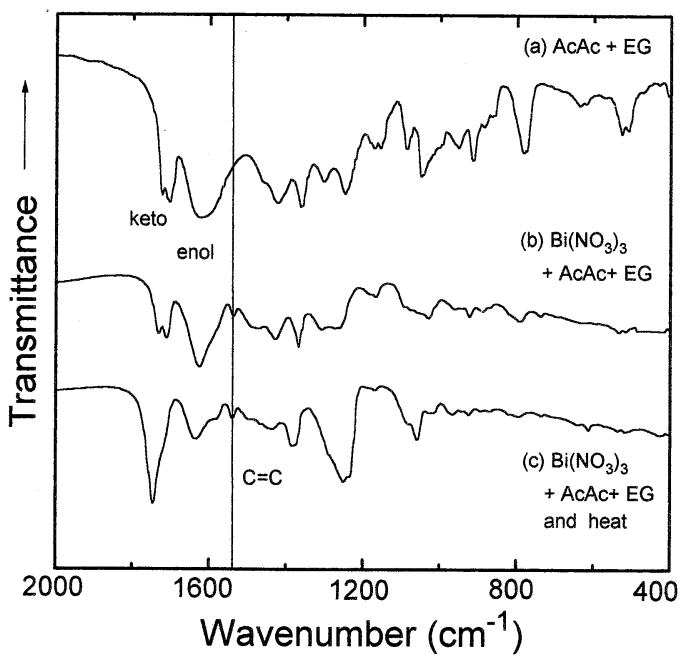

Fig. 2. IR spectra of (a) AcAc-EG, (b) $\mathrm{Bi}\left(\mathrm{NO}_{3}\right)_{3} \cdot 5 \mathrm{H}_{2} \mathrm{O}-\mathrm{AcAc}-$ $\mathrm{EG}$ and (c) $\mathrm{Bi}\left(\mathrm{NO}_{3}\right)_{3} \cdot 5 \mathrm{H}_{2} \mathrm{O}-\mathrm{AcAc}-\mathrm{EG}$ heat-treated at $120^{\circ} \mathrm{C}$.

axis oriented thin film with the composition of $\mathrm{Bi}_{4} \mathrm{Ti}_{3} \mathrm{O}_{12}$ (BIT). Therefore, the thin films were prepared by changing following heat treatment conditions on $\mathrm{SiO}_{2} / \mathrm{Si}$ substrate.

(1) Thin film was prepared by spin coating and then pre-heat-treatment at $250^{\circ} \mathrm{C}$ and heat treatment at $800^{\circ} \mathrm{C}$, and this procedure was repeated several times.

(2) Thin film was prepared by spin coating and then pre-heat-treatment at $250^{\circ} \mathrm{C}$ and this procedure was repeated several times and further heat treatment at $800^{\circ} \mathrm{C}$.

(3) Thin film was prepared by spin coating and then after drying this procedure was repeated several times and heat treatment at $800^{\circ} \mathrm{C}$ by rapid heating.

Figure 3 shows X-ray diffraction patterns of thin films prepared on $\mathrm{SiO}_{2} / \mathrm{Si}$ substrate at above conditions. The peaks of highly $c$-axis oriented films were observed for thin films prepared after pre-heat-treatment at about $120^{\circ} \mathrm{C}$ of a sol. It was considered from this result that the pre-heattreatment at about $120^{\circ} \mathrm{C}$ of a sol suppressed the formation of pyrochlore $\mathrm{Bi}_{2} \mathrm{Ti}_{2} \mathrm{O}_{7}$ phase.

Figure 4 shows X-ray diffraction pattern of BIT thin film heat-treated at $700^{\circ} \mathrm{C}$ on platinum substrate. The thin film showed only (001) diffraction lines; the observation indi-

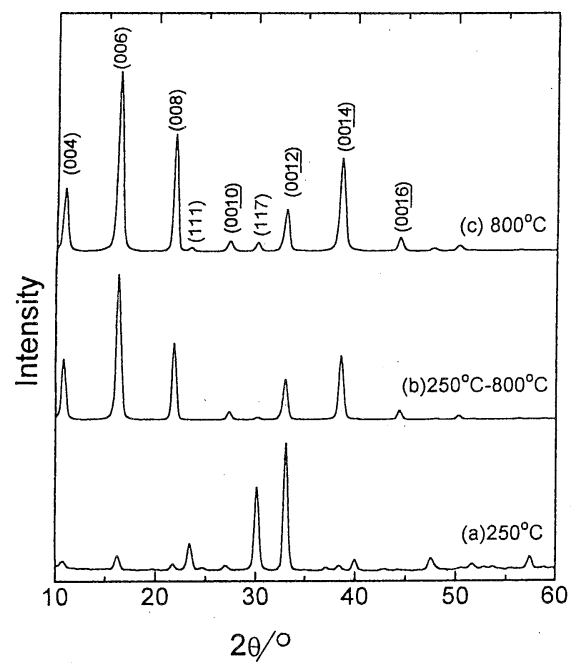

Fig. 3. X-ray diffraction patterns of BIT films prepared on $\mathrm{SiO}_{2} /$ Si by sintering at $800^{\circ} \mathrm{C}$ after heat treatment at (a) $250^{\circ} \mathrm{C}$, (b) $250-$ $800^{\circ} \mathrm{C}$ and (c) $800^{\circ} \mathrm{C}$. 


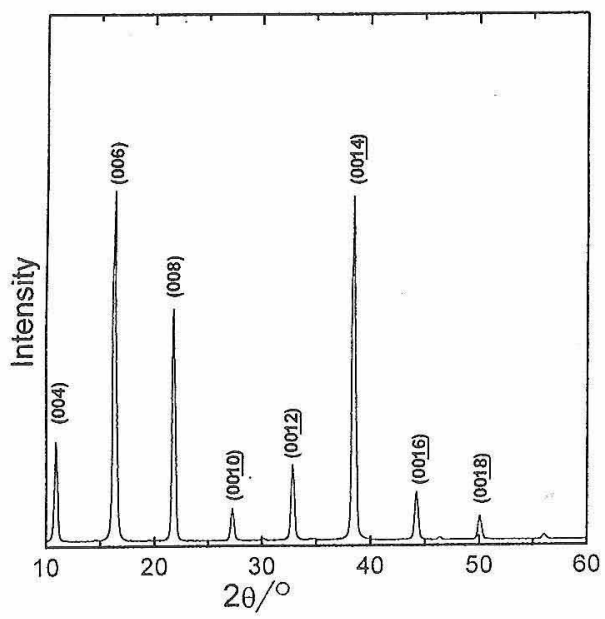

Fig. 4. X-ray diffraction pattern of BIT film prepared on Pt by heat treatment at $700^{\circ} \mathrm{C}$.

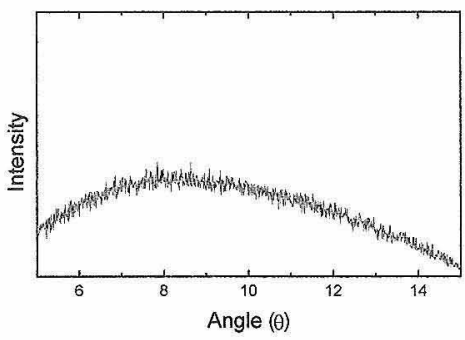

(a) on $\mathrm{SiO}_{2} / \mathrm{Si}$

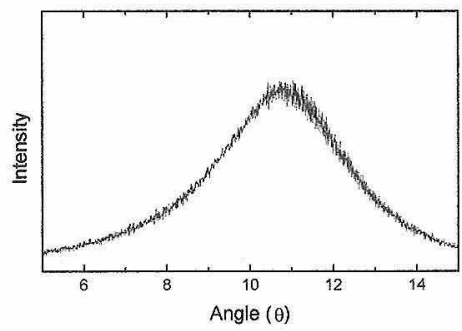

(b) on platinum

Fig. 5. Rocking curves of (008) plane of BIT films prepared on (a) $\mathrm{SiO}_{2} / \mathrm{Si}$ and (b) Pt.

cates that the $c$-axis of BIT grain in the film orientates perpendicular to the surface of the substrate. In order to examine the effect of substrate upon the degree of preferential orientation of the BIT grain, X-ray rocking curve was measured (Fig. 5). The peak with the FWHM of $3^{\circ}$ was observed in the rocking curve for the film prepared on platinum substrate, whereas any clear peak was not observed for the film prepared on $\mathrm{SiO}_{2} / \mathrm{Si}$ substrate. The appearance of a peak in the rocking curve depends highly on the crystallinity of the respective BIT grains and/or the degree of the preferential orientation. Thus, from the experimental observations, we recognized that the usage of platinum substrate had some advantages in the preparation of highly oriented BIT thin films rather than that prepared by use of $\mathrm{SiO}_{2} / \mathrm{Si}$ substrates.

Figure 6 shows AFM pictures of thin film surface prepared on $\mathrm{SiO}_{2} / \mathrm{Si}$ and platinum substrates. For thin film prepared on $\mathrm{SiO}_{2} / \mathrm{Si}$, the grains with about $0.1 \mu \mathrm{m}$ size were formed in thin films by ten times coating. On the other

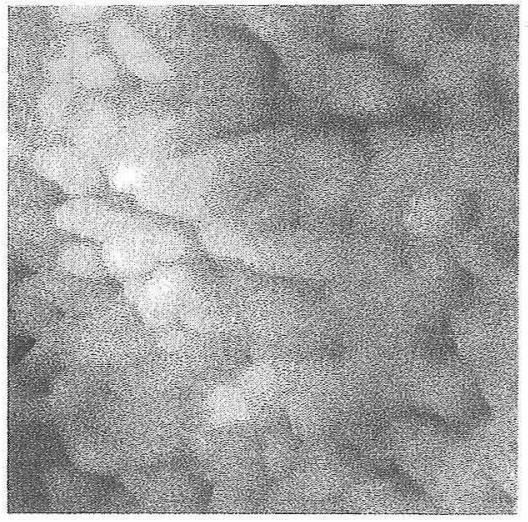

(a) on $\mathrm{SiO}_{2} / \mathrm{Si}$

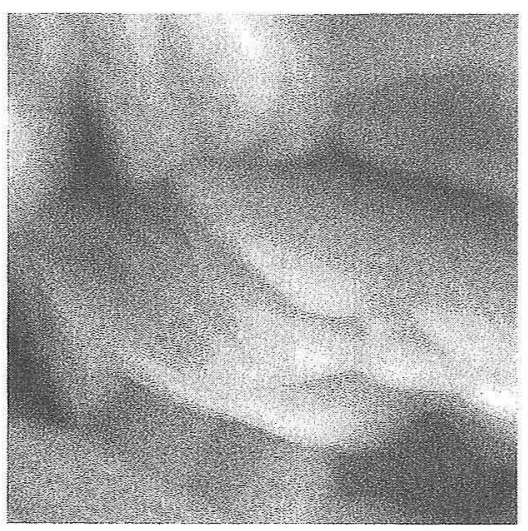

$0.5 \mu \mathrm{m}$

(b) on $\mathrm{Pt}$

Fig. 6. AFM pictures of BIT films prepared on (a) $\mathrm{SiO}_{2} / \mathrm{Si}$ and (b) Pt.

hand, the platelike crystal with about $1.0 \mu \mathrm{m}$ size were formed in thin film prepared on platinum substrate. These crystals were similar with highly oriented ceramics prepared by hot-forged process. ${ }^{14)}$ The growth conditions of the oriented crystal grains showed largely different for both substrates.

Moreover, during $120^{\circ} \mathrm{C}$-heat treatment, hydrolysis and condensation reactions continue to produce longer polymer. These polymers can reach to the sufficient length that they can be oriented parallel to the substrate surface during spinning.

For used polycrystal metal substrate, it was reported that the oriented thin film was obtained when the lattice length of some direction in the thin film crystal and lattice constant was longer. ${ }^{15}$ ) The lattice constant of platinum is 0.392 $\mathrm{nm}^{1)}$ and that of BIT at room temperature is not close to that of platinum. But the lattice constant of BIT is $0.386 \mathrm{~nm}$ when BIT is transformed in tetragonal at higher temperature than Curie point. Therefore $c$-axis oriented thin film may be obtained by the approach of the lattice constant of BIT thin film and platinum substrate by the heat treatment at $700^{\circ} \mathrm{C}$.

\subsection{Electrical properties of thin films}

Figure 7 shows film thickness dependence of dielectric constant prepared on platinum substrate by heat treatment at $700^{\circ} \mathrm{C}$ for $16 \mathrm{~h}$. The dielectric constant increased with increasing of film thickness, but inversely decreased at 2.5 $\mu \mathrm{m}$ thickness. And, dielectric constant of highly $c$-axis oriented films was smaller than those of lower oriented films on $c$-axis. Figure 8 shows $P-E$ hysteresis loops of BIT 


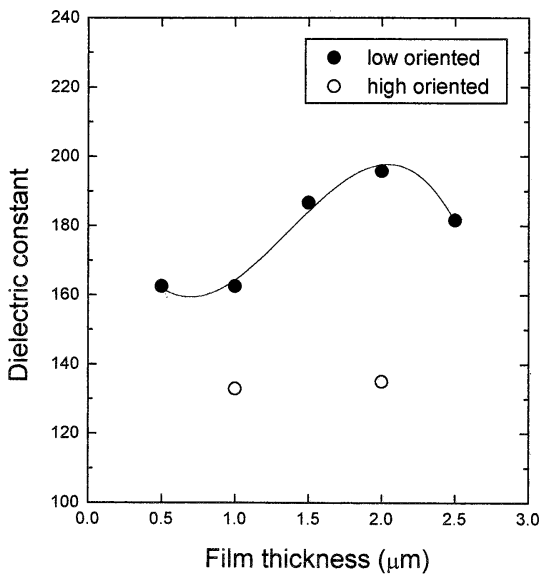

Fig. 7. Film thickness dependence of dielectric constant of BIT films prepared on $\mathrm{Pt}$ by heat treatment at $700^{\circ} \mathrm{C}$ (measured at 150 $\mathrm{kV} / \mathrm{cm})$.

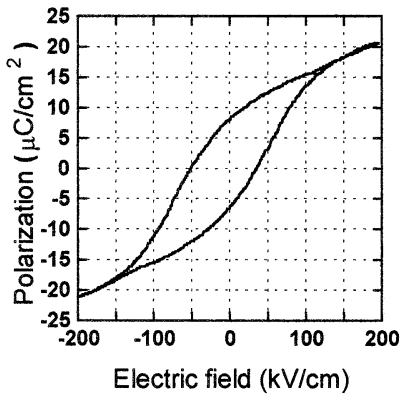

(a) low oriented

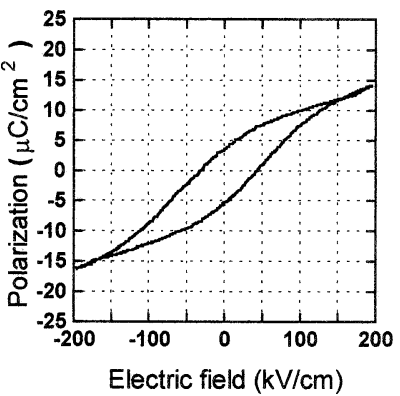

(b) high oriented
Fig. 8. Hysteresis loops of BIT films prepared on Pt by heat treatment at $700^{\circ} \mathrm{C}$ with $2 \mu \mathrm{m}$ thickness (measured at $150 \mathrm{kV} / \mathrm{cm}$ ).

films with $2 \mu \mathrm{m}$ thickness on platinum substrate. An applied voltage to specimen was constant at about $15 \mathrm{~V} /$ $\mu \mathrm{m}(150 \mathrm{kV} / \mathrm{cm})$. As like as dielectric constant, the higher $c$-axis orientation of film, the smaller remanent polarization $\left(P_{\mathrm{r}}\right)$ and coercive field $\left(E_{\mathrm{c}}\right)$ of films were observed. Remanent polarization, $P_{\mathrm{r}}=2.5 \mu \mathrm{C} / \mathrm{cm}^{2}$ of highly $c$-axis oriented thin film was smaller than that of single crystals and $E_{\mathrm{c}}$ $=25 \mathrm{kV} / \mathrm{cm}$ was larger than that of single crystals. It was considered from that the grain boundary in thin film increased and the orientation of thin film decreased with increasing film thickness.
In comparison with MOCVD methods, the preparation of BIT thin films by sol-gel process is very easy. The highly $c$ axis oriented thin films obtained in this study leads to lower coercive field and make the inversion of the polarization by lower electric field easy. Therefore it is considered that the prepared highly $c$-axis oriented thin film may be very useful for application to memory materials.

\section{Conclusion}

(1) Highly $c$-axis oriented BIT thin film have been successfully prepared on platinum substrate heat-treated at $700^{\circ} \mathrm{C}$ by a sol-gel spin-on-coating technique.

(2) The crystal grains shows very large difference with grain size and shape due to the effect of $\mathrm{SiO}_{2} / \mathrm{Si}$ and platinum substrates.

(3) The ferroelectricity of thin film prepared on platinum substrate were changed with increasing the orientation of thin films. Namely, $P_{\mathrm{r}}$ and $E_{\mathrm{c}}$ decreased with increasing $c$-axis orientation. Dielectric constants were 135-195 (at $10 \mathrm{kHz}$ ), $P_{\mathrm{r}}$ was $2.5-6 \mu \mathrm{C} / \mathrm{cm}^{2}$ and $E_{\mathrm{c}}$ was $25-35 \mathrm{kV} /$ $\mathrm{cm}($ at $50 \mathrm{~Hz}, 150 \mathrm{kV} / \mathrm{cm})$.

(4) The key technique to highly textured films are heat treatment of sol prepared by optimum combination of raw materials and solvent.

\section{References}

1) E. C. Subbarao, Phys. Rev. 122, 804-07 (1961).

2) D. Dimos, P. Claudhari, J. Mannhart and F. K. Legoues, Phys. Rev. Lett., 61, 219 (1988).

3) M. H. Francombe, Ferroelectrics, 3, 199-211 (1972).

4) P. K. Ghosh, A. S. Bhalla and L. E. Cross, J. Mater. Sci., 29, 4659-62 (1994).

5) Y. Masuda, A. Baba, H. Matsumoto, T. Goto, M. Minakata and T. Hirai, Jpn. J. Appl. Phys., 30, 2212-15 (1991).

6) M. Toyoda, Y. Hamaji, K. Tomono and D. A. Payne, Jpn. J. Appl. Phys., 32, 4158-62 (1993).

7) P. Joshi and S. Krupanidhi, Appl. Phys. Lett., 62, 1928 (1993).

8) P. Fuierer, S. Shan and L. Liu, Ceramics Transaction, 44, 199-206 (1995).

9) H. Buhay, S. Sinharoy, W. Kansner, M. Francombe, D. Lampe and E. Stepke, Appl. Phys. Lett., 58, 1470 (1991).

10) N. Maffei and S. Krupanidhi, J. Appl. Phys., 72, 3617 (1992).

11) A. Kakimi, S. Okamura and T. Tsukamoto, Jpn. J. Appl. Phys., 33, 1707-09 (1994).

12) A. Kakimi, S. Okamura, S. Ando and T. Tsukamoto, Jpn. J. Appl. Phys., 34, 5193-97 (1995).

13) K. Yoshimura, M. Ishinabe, S. Okamura and T. Tsukamoto, Jpn. J. Appl. Phys., 34, 2425-29 (1995).

14） T. Takenaka and K. Sakata, Jpn. J. Appl. Phys., 19, 31-39 (1980).

15) K. Kousu, "Thin Film Coating Technology by Sol-Gel Method", Technology Information Soc. (1994) pp. 23-28. 